\title{
O circo como dispositivo cultural na musicalidade de Milton Nascimento com crianças
}

\author{
Alberto Carlos de Souza*
}

Resumo: Oficina de cultura realizada com 25 crianças de 9 anos de idade, estudantes de uma escola pública municipal de Vitória - ES, e que teve como propósito celebrar o Dia Internacional Circo, em 27 de março. Toda a produção estética dessa oficina girou em torno da música "Circo Marimbondo", de autoria de Milton Nascimento e Ronaldo Bastos (1978) e constou de canto coral e elaboração de pictografias de artistas circenses (desenho com massa de modelar), a partir da questão norteadora: "Quem são esses marimbondos, de que tanto fala a música?” Os marimbondos foram representados pelas crianças principalmente como figura de artistas fantásticos como palhaços, bailarinas, homembala, trapezista e mulher barbada ou mulher gorila. A oficina culminou com a apresentação de toda a produção estética (canto coral e projeção de imagens) para a família daquelas crianças. Palavras-chave: Arte, Música Popular Brasileira, Crianças, Cultura.

Abstract: Workshop by culture carried out with 25 children from 9 years old, students at a local public school in Vitória - ES, which aimed to celebrate the International Day Circus on March 27. All the aesthetic production of the workshop revolved around

* Doutorando em Humanidades, pela Universidad Nacional de Rosario (UNR)Argentina. Mestre em História pela Universidade Salgado de Oliveira- Universo. Professor de Arte da Secretaria de Educação de Vitória/Serra-ES. E-mail: acsouza71@bol.com.br 
the song "Circus Wasp", by Milton Nascimento and Ronaldo Bastos (1978) and consisted of choral sing and elaboration of pictography of circus artists (drawing with clay modeling), from question: "Who are these wasps whose music speaks so much?" The wasps were represented mainly by children like it features amazing artists as: clowns, dancers, man bullet, trapeze artists, and bearded woman or female gorilla. The workshop culminated with the presentation of the whole aesthetic production (choral and projection of images) to the family of those children.

Keywords: Art, Brazilian Popular Music, Children, Culture.

\section{Introdução}

Esta experiência buscou relatar as representações sociais que um grupo de 25 crianças de nove anos de idade, estudantes do $4^{\circ}$ Ano da Escola Municipal de Ensino Fundamental (EMEF) Prof. Vercenílio da Silva Pascoal, no Município de Vitória/ES -, têm sobre o circo como espaço cultural. Tal estudo constituiu-se como a primeira parte de um projeto que teve, como motivação para criar um espaço estético para discussão, em nossa escola, o circo como dispositivo de Resistência Cultural. É preciso resgatar esse espaço singular que o circo representa na contemporaneidade como um lugar de fantasia. Quando os artistas estendem a famosa lona azul, o cotidiano das crianças muda num piscar de olhos, maravilhadas pela sedução da plateia como o lugar do fantástico. São personagens de um "mundo encantador", um mundo que não é o real, pelo menos para a plateia que sonha e se deixa sonhar.

Para Hall (2006), na modernidade reflexiva em que vivemos, o homem - diferente da concepção iluminista ou sociológica -, é um sujeito descentrado e que vive em crise de identidade, visto que as velhas identidades estão continuamente sendo substituídas por novas identidades. Nessa perspectiva, o autor parte de três concepções de sujeitos construídos e assumidos ao longo do processo histórico que determina as identidades, a saber: 
- O sujeito iluminista: aquele que era centrado, possuindo uma concepção individualizada na qual o centro essencial do "Eu" correspondia à sua identidade;

- O sujeito sociológico: aquele que rompeu com essa concepção na medida em que passou por transformações de ideias, de pensamentos, a partir de onde começou a interagir com a sociedade;

- O sujeito pós-moderno: aquele que faz ruptura com a concepção sociológica, quando é perturbado com as mudanças estruturadas e institucionais, assumindo identidades diferentes em diferentes momentos.

Dessa forma, Hall (2006) entende que no tempo em que vivemos, marcado pela globalização, a crise de identidade é inevitável. Assim posto, entendemos ser função da escola criar junto ao alunado um espaço de valorização de seu patrimônio cultural, e para tal consideramos a teoria dos lugares de memória - conforme proposição de Nora (1984), em que a teoria dos lugares da memória foi formulada e desenvolvida a partir dos seminários orientados por Nora na École Pratique de Hautes Etudes, de Paris, entre 1978 e 1981, sendo editada em "Les Lieux de Mémorie", uma obra composta por quatro volumes. Reportando-se à memória nacional francesa, Nora, nessa obra, considera ser importante inventariar os lugares onde a memória - cada vez mais ameaçada de desaparecer -, ainda permanece encarnada.

Há de se considerar, ainda, que na concepção pedagógica atual, existe uma indissolubilidade entre educação e cultura,

[...] porque a educação como formação e instrumento de participação precisa partir das potencialidades do educando e motivá-lo à criatividade própria. A cultura constitui o contexto próprio da educação, porque é motivação fundamental para a mobilização comunitária e quadro concreto da criatividade histórica (DEMO, 1993, p. 58).

A LDB prescreve que, entre outros conhecimentos, o ensino de Arte e da História constituem componentes curriculares obrigatórios, nos diversos níveis da educação fundamental, de forma a promover a consciência e o desenvolvimento cultural 
- local e universal -, dos alunos. De acordo com a referida lei, o ensino deverá valorizar a experiência extracurricular dos educandos, e foi nessa perspectiva que se inseriu esse processo interdisciplinar que foi viabilizado por essas disciplinas com os alunos matriculados nas duas turmas da oitava série da referida escola. O Convento da Penha (re) nasce com envolvimento dos alunos e das disciplinas Educação Artística e História, esteve em concordância com as recomendaçôes dos Parâmetros Curriculares Nacionais (PCN), uma vez que:

É fundamental que a escola assuma a valorização da cultura de seu próprio grupo $[\ldots]$ buscando ultrapassar seus limites, propiciando às crianças e aos jovens pertencentes aos diferentes grupos sociais o acesso ao saber [...] relevantes da cultura brasileira no âmbito nacional e regional como no que faz parte do patrimônio universal da humanidade (BRASIL, 1998, p. 44).

\section{História do circo}

O primeiro circo europeu moderno, o Astley's Amphitheatre, foi inaugurado em Londres por volta de 1770 por Philip Astley, um oficial inglês da Cavalaria Britânica. O circo de Astley tinha um picadeiro com uma espécie de arquibancada perto. Construiu um anfiteatro suntuoso e fixo, pois ficaria permanentemente no mesmo lugar. Organizou um espetáculo equestre, com rigor e estrutura militares, mas percebeu que para segurar o público, teria que reunir outras atrações e juntou saltimbancos, equilibristas, saltadores e palhaço. $\mathrm{O}$ palhaço do batalhão era um soldado campônio, que acaba sendo o clown, palavra que em inglês se origina de caipira. $\mathrm{O}$ palhaço não sabia montar, entrava no picadeiro montado ao contrário, caía do cavalo, subia de um lado, caía do outro, passava por baixo do cavalo. Como fazia muito sucesso, começaram a se desenvolver novas situações. Ao longo dos anos, Astley acrescentou saltos acrobáticos, a dança com laços e malabarismo. 
Esse primeiro circo funcionava como um quartel: os uniformes, o rufar dos tambores, as vozes de comando para a execução dos números de risco. O próprio Astley dirigia e apresentava o espetáculo, criando assim, a figura do mestre de cerimônias. Seu espetáculo foi visto por gente de todo mundo, pois Londres era muito visitada. E em 50 anos, houve um rápido desenvolvimento do circo no mundo.

O termo circus foi utilizado pela primeira vez em 1782, quando o rival de Astley, Charles Hughes, abriu as portas do Royal Circus. Em princípios do século XIX havia circos permanentes em algumas das grandes cidades europeias. Existiam, além disso, circos ambulantes, que se deslocavam de cidade em cidade em carretas cobertas. No Brasil, mesmo antes do circo de Astley, já havia os ciganos que vieram da Europa, onde eram perseguidos. Sempre houve ligação dos ciganos com o circo. Entre suas especialidades incluíam-se a doma de ursos, o ilusionismo e as exibições com cavalos. Há relatos de que eles usavam tendas e nas festas sacras, havia bagunça, bebedeira e exibições artísticas, incluindo teatro de bonecos. Eles viajavam de cidade em cidade e adaptavam seus espetáculos ao gosto da população local. Números que não faziam sucesso na cidade eram tirados do programa.

O circo com suas características, em geral itinerante, existem no Brasil a partir dos fins do século XIX. Desembarcavam em um porto importante, faziam seu espetáculo, partiam para outras cidades, descendo pelo litoral até o rio da Prata, indo para Buenos Aires. Instalando-se na periferia das grandes cidades e voltado para as classes populares, sua modernização não se deu em termos de espaços e equipamentos: investem no elemento humano, suas destrezas, habilidades e criatividade. Por isso, os palhaços são as figuras centrais, dependendo deles o sucesso do circo.

O circo brasileiro tropicalizou algumas atraçôes. O palhaço brasileiro falava muito, ao contrário do europeu, que era mais mímico. Era mais conquistador e malandro, seresteiro, tocadores 
de violão, com um humor picante. O público também apresentava características diferentes: os europeus iam ao circo apreciar a arte; no Brasil, os números perigosos eram as atrações: trapézio, animais selvagens e ferozes.

Segundo Alice Viveiros de Castro ${ }^{1}$, atualmente existem mais de 2.000 circos espalhados pelo Brasil, sendo aproximadamente 80 médios e grandes, com trapézio de vôos, animais e grande elenco. Estima-se um público anual de 25 milhões de espectadores. Entre os problemas enfrentados nos dias de hoje estão os terrenos caros e há cidades que não permitem a montagem de circos, pois seus prefeitos temem estes "forasteiros".

Nos dias de hoje, paralelamente aos circos itinerantes e tradicionais que ainda existem, a arte circense também se aprende em escolas. Por uma mudança de valores, muitos circenses colocaram seus filhos para estudar e fazer um curso universitário. As novas gerações estão trabalhando mais na administração dos circos. Surge um novo movimento, que pode ser chamado de Circo Contemporâneo. Não há uma data precisa do seu surgimento, mas pode-se dizer que o movimento começou no final dos anos 70, em vários países simultaneamente. Na Austrália, com o Circus Oz (1978), e na Inglaterra, com os artistas de rua fazendo apresentaçôes de palhaços, mostrando truques com fogo, andando em pernas de pau e fazendo suas mágicas.

$\mathrm{Na}$ França, a primeira escola de circo é a Escola Nacional de Circo Annie Fratellini. Annie era descendente da maior família de palhaços franceses, os Fratellini. A escola surge com o apoio do governo francês, em 1979. Ligados à escola ou não, começam a surgir vários grupos. No Canadá, os ginastas começaram a dar aulas para alguns artistas performáticos e a fazer programas especiais para a televisão e em ginásios em que os saltos acrobáticos

Atriz, diretora de teatro, especialista em circo - se autodefinindo como acrobata mental. De acordo com sua apresentação, foi também: vedete de teatro de revista com Luiz Mendonça, contra-mestra do Pastoril, comediante de televisão. Autora do livro: O Elogio da Bobagem - palhaços no Brasil e no mundo (São Paulo: Família Bastos/Petrobras, 2005). Seu blog: acrobatasmentais.blogspot.com. 
eram mais circenses. Em 1981, criou-se a primeira escola de circo para atender à demanda dos artistas performáticos.

Em 1982, surge em Québec o Club des Talons Hauts, grupo de artistas em pernas de pau, malabaristas e pirofagistas. É esse grupo que em 1984 realiza o primeiro espetáculo do Cirque du Soleil. Em decorrência do grande sucesso no Canadá, eles recebem apoio do governo para a primeira turnê nos Estados Unidos. A segunda turnê, em 1990, é assistida por 1.300 .000 espectadores no Canadá e excursiona por 19 cidades americanas. Surge a grande empresa de espetáculos que atualmente está em cartaz com oito espetáculos diferentes no mundo, em três continentes, com mais de 700 artistas contratados.

Voltando um pouco na história, é importante mencionar a influência da ex-URSS. Em 1921, o novo governo soviético resolve criar uma escola de circo e convida o prestigiado diretor de teatro Vsevolod Meyherhold para dirigi-la. O contato entre os tradicionais do circo e a vanguarda do teatro resulta na criação de uma escola que coloca o circo num patamar de arte. Dança clássica e teatro fazem parte do currículo. É criada uma forma de espetáculo com temas e uma apresentação inteiramente novas. São criados novos aparelhos, diretores são chamados para dirigir os espetáculos, os músicos fazem composições especiais e sob medida.

A primeira escola Contemporânea Circense, que se instalou no Brasil chamava-se Piolin, em São Paulo, no estádio do Pacaembu (1977). Em 1982, surgiu a Escola Nacional de Circo, no Rio de Janeiro, onde jovens de todas as classes sociais têm acesso às técnicas circenses. Formados, os ex-alunos vão trabalhar nos circos brasileiros ou no exterior, ou formam grupos que se apresentam em teatros, ginásios e praças. Atualmente, a Intrépida Trupe, os Acrobáticos Fratelli, os Parlapatões, Patifes e Paspalhões, a Nau de Ícaros, o Circo Mínimo, o Circo Escola Picadeiro, as Linhas Aéreas e o Teatro de Anônimo, entre outros, formam o Circo Contemporâneo Brasileiro. 
Continuemos falando de circo. Um outro circo, o circo humano, um circo contemporâneo no qual o palhaço corre um risco que pode ser simbólico ou real:

Às vezes o risco é símbolico (a queda da bola do malabarista ou ainda o comportamento desequilibrado do clown), mas o risco que se corre na cena é, na maior parte do tempo, real e vital, colocando em causa a integridade física do artista. A vida é colocada em jogo na cena, e a morte - para ser julgada? - é verdadeira e frequentemente convocada (GOUDARD, 2009, p. 25).

Sobre este relato, especificamente, tratou-se de um projeto implementado à luz dos Parâmetros Curriculares Nacionais (PCN) - um documento editado pelo Ministério da Educação e que oferece as balizas para se construir uma referência curricular nacional para o ensino fundamental. Dentre as suas muitas recomendações esse documento recomenda aos educadores que

[...] as crianças e os jovens deste país desenvolvam suas diferentes capacidades, enfatizando que a apropriação dos conhecimentos socialmente elaborados é a base para a construção da cidadania e da sua identidade, e que todos são capazes de aprender e mostrar que a escola deve proporcionar ambientes de construção dos seus conhecimentos e de desenvolvimento de suas Inteligências com suas múltiplas competências (BRASIL, 1998, p. 10-11).

Tais PCN prescrevem também que os temas sociais urgentes - chamados Temas Transversais - devam ser desenvolvidos de maneira interdisciplinar no ensino fundamental (BRASIL, 1998). De acordo com os referidos PCN, é necessário que os docentes atuem com a diversidade existente entre os alunos e que com os seus conhecimentos prévios sirvam como fonte de aprendizagem de convívio social e não apenas como um meio de aprendizagem de conteúdos específicos (BRASIL, 1998).

Assim posto, entendermos que as questões relacionadas ao Circo - aqui incluídos os atores e sua relação com o trabalho constituem um tema social urgente. Como forma de celebrar o Dia do Circo na escola, propusemos este projeto interdisciplinar, 
deixando emergir as representações das crianças sobre o Circo como lugar de resistência cultural.

Conforme observam Cheire e Bulir (2001), as representações são construções simbólicas que norteiam as atividades. Tais representações são elaboradas coletiva e socialmente pelos atores sociais e servem para os mesmos nomearem, apreenderem e transformarem o seu meio ambiente. Essas representações circulam e transformam-se principalmente por meio das relações de comunicação desenvolvidas entre os atores sociais. Sobre as representações sociais - uma forma de conhecimento prático que se inserem muito bem entre as correntes que estudam o senso comum -, Moscovici (1978, p. 26) as definem como "uma modalidade de conhecimento particular que tem por função a elaboração de comportamentos e a comunicação entre os indivíduos", visto que constituem "um corpus organizado de conhecimentos" e uma das atividades psíquicas graças às quais os homens tornam inteligível a realidade física e social, inserem-se num grupo ou numa ligação cotidiana de trocas, liberando os poderes de sua imaginação (MOSCOVICI, 1978, p. 28).

Na elaboração do referido projeto, o nosso propósito foi o de deixar emergir as representações que as crianças - enquanto atores sociais cheios de conhecimentos prévios - tinham sobre o Circo. Para tal nos apropriamos da música "Circo Marimbondo", de autoria de Nascimento e Bastos (1976), como ponto de partida da nossa intervenção, por entendermos que essa letra é um hino de amor a todos que fazem parte dos circos (in)comuns brasileiros, que, assim como aquelas trabalhadoras norteamericanas de 1857, ainda lutam por fazer valer os seus direitos e participam da construção do nosso cotidiano social.

Apoiados pela musicalidade da interpretação de "Circo marimbondo", num dueto nas vozes de Milton Nascimento e Clementina de Jesus, buscam através do desenvolvimento da tensão psíquica das crianças, darem visibilidade às representações que as mesmas têm sobre o circo. Utilizamos para tal a linguagem estética, compreendida pela sua dimensão plástica e musical. 
Sobre o conceito de tensão psíquica, tão essencial ao processo de criação, Ostrower (1987, p. 27-28) observa que

criar não representa um relaxamento ou um esvaziamento pessoal, nem uma substituição imaginativa da realidade; criar representa uma intensificação do viver, um vivenciar-se no fazer; e, em vez de substituir a realidade, é a realidade; é uma realidade nova que adquire dimensões novas pelo fato de nos articularmos, em nós e perante nós mesmos, em níveis de consciência mais elevados e mais complexos. Somos, nós, a realidade nova. Daí o sentimento do essencial e necessário no criar, o sentimento de um crescimento interior, em que nos ampliamos em nossa abertura para a vida.

O ponto de partida do projeto foi o alcance do seguinte objetivo: conhecer as representações sociais que crianças têm sobre o circo enquanto cultura de resistência, tendo como referência a música "Circo marimbondo", de Milton Nascimento e Ronaldo Bastos (1976).

\section{Metodologia}

Tratou-se de uma experimentação estética de caráter histórico, plástico, teatral e musical, enquanto intervenção de ensino-aprendizagem interdisciplinar (Arte - Ensino básico fundamental), em uma escola de ensino fundamental de Vitória. A intervenção teve como cenário a Escola Municipal de Ensino Fundamental (EMEF) Prof. Vercenílio da Silva Pascoal, da Rede Municipal de Educação de Vitória/ES. O universo dessa intervenção foi constituído pelos 25 estudantes da turma única do $4^{\circ}$ ano do Ensino Fundamental da referida escola. $\mathrm{O}$ trabalho foi realizado através de atividades de laboratório e constou dos seguintes momentos:

$\left.1^{\circ}\right)$ Leitura compreensiva da letra "Circo Marimbondo" (Anexo), buscando esclarecer termos ou expressões desconhecidas pelas crianças;

$2^{\circ}$ ) Audição silenciosa da música; 
$3^{\circ}$ ) Memorização da letra da música, através da escuta e canto simultâneo, e

$4^{\circ}$ ) Representação do circo ou dos personagens que o integram, através da técnica de desenho com massa de modelar, a partir da seguinte questão norteadora: Quem são esses marimbondos, de quem tanto fala a música?

Para a elaboração do relatório dessa experimentação estética tomamos como suporte a Análise de Conteúdo, entendida como,

[...] um conjunto de técnicas de análise das comunicaçôes visando obter, por procedimentos sistemáticos e objetivos de descrição de conteúdo das mensagens, indicadores (quantitativos ou não) que permitam interferência de conhecimentos relativos às condições de produção/recepção (variáveis inferidas) dessas mensagens (BARDIN, 2000, p. 42).

\section{O circo e seus marimbondos...}

Nem todos os fenômenos sociais são formadores de Representações Sociais. Uma Representação Social surge onde houver perigo para uma identidade coletiva e traduz a relação de um grupo com um objeto socialmente valorizado. Assim, toda Representação Social é a representação de algo e/ou de alguém por alguém. Nossa opção por esse quadro teórico ficou assim justificada: a representação de alguém - o circo - por um grupo de crianças. Mas afinal, quem são essas crianças? São, conforme nos apresenta Del Priore (2006), crianças brasileiras como aquelas que estão em toda parte, com destinos variados e variados rostos: rostinhos mulatos, brancos, negros e mestiços. Algumas amadas e outras simplesmente usadas.

A partir das cenas de produção estética elaboradas por aquelas crianças, através da técnica de desenho com massa de modelar em papel branco, construímos cinco categorias analíticas que nos deram conta de compreender que, para essas crianças, Maria faz-se representar, nesta ordem, principalmente como:

1) figura do palhaço (palhaço $=8$ referências); 
2) bailarina (bailarina $=6$ referências);

3) homem bala (homem bala $=4$ referências);

4) trapezista (trapezista $=4$ referências);

5 ) mulher barbada (mulher barbada $=2$ referência). $\mathrm{E}$ por fim;

6) conga a mulher gorila (mulher gorila $=1$ referência).

Podemos evidenciar que nesse estudo, a representação dos artistas do circo como figura de palhaço - palhaço - ou como bailarina são as que mais se sobressaem, denotando a importância da família e do lúdico na vida dessas crianças.

Sobre a família, D’Inácio (2004) observa que foi a partir do século XIX, época marcada pelo início da urbanização brasileira, que a mulher faz uma nova leitura, pela primeira vez em nosso contexto histórico, o seu lugar nas relações da chamada família burguesa, fortemente valorizada pelos sentimentos de intimidade e maternidade e de cultura. Dessa forma, o Circo passa a fazer parte de um lugar de memória e de resistência ambiente familiar, pode inserir a cultura de resistência para que não extinga o circo do lúdico dessas crianças, pois, é identidade cultural, tendo como função a família de propiciar cultura local de suas crianças dos "filhos educados e (ser) esposa dedicada ao marido, às crianças e desobrigadas de qualquer trabalho produtivo, representavam o ideal de retidão e probidade, um tesouro social imprescindível" (D’INACIO, 2004, p. 223).

Tal concepção de sociedade, reservando "ao homem, o universo do público, o trabalho remunerado, o papel de provedor econômico da família, a racionalidade, a fibra [...], à mulher, o universo do privado, o trabalho não remunerado do lar, o cuidado com os filhos, a sensibilidade, a fragilidade" (SOUZA, 1997, p. 182) foi algo que perdurou ao longo dos séculos. Trata-se, no entanto, de uma visão burguesa da sociedade brasileira, pois nas camadas de baixo poder aquisitivo as mulheres, em todos os tempos sempre estiveram inseridas no mercado de trabalho e hoje algumas são as mantenedoras dos seus lares, por isso, geralmente proporcionam a seus filhos entretenimento cultural. 
No presente estudo, as crianças referem os marimbondos do circo como um personagem fantástico - geralmente inserida em ocupações pertencentes ao setor de artista: o marimbondo é palhaço, ou bailarina, ou homem bala, ou trapezista, ou a mulher barbada, ou Conga, a mulher gorila. Em relação à inserção da família a mulher de classes menos favorecidas no trabalho, temos de considerar que historicamente as mesmas sempre foram pressionadas a obter remuneração: "As empregadas domésticas [...] existem desde o fim da escravatura. No campo, as mulheres sempre estiveram presentes na lavoura, basta ver qualquer ilustração de colheitas de café ou cana de açúcar para constatá-lo..." (SOUZA, 1997, p. 182).

A finalização do projeto se deu através de um encontro de socialização do que foi trabalhado com as mães das crianças: as crianças receberam suas mães cantando em coro a canção "Circo Marimbondo”. Simultaneamente, as representações elaboradas foram apresentadas em uma tela.

\section{Considerações Finais}

O ponto de partida dessa intervenção consistiu na exploração da musicalidade de Milton Nascimento, protagonista do "movimento" Clube da Esquina, que floresceu em Minas Gerais, a partir da década de 60 , no auge de um dos períodos mais críticos da história contemporânea brasileira: a ditadura militar (BORGES, 1996). Dentre o seu conjunto da obra, nossa opção se deu pela música "Circo Marimbondo". As representações sociais do circo, aqui apresentadas, são entidades quase tangíveis que "circulam, cruzam-se e se cristalizam incessantemente através de uma fala, um gesto, um encontro" (MOSCOVICI, 1978, p. 41), no universo cotidiano dessas crianças.

O estudo evidenciou que, para essas crianças, os marimbondos se fazem representar como aquele artista fantástico, representado por Milton Nascimento, em sua infância de menino 
negro, filho adotivo, criança traquina, tão igual a muitas das crianças que freqüentam as nossas escolas de periferia: Marimbondo é palhaço, ou a bailarina, ou um homem bala, ou trapezista, ou uma mulher barbada - simplesmente -, uma mulher gorila!

\section{Referências}

BARDIN, Laurence. Análise de conteúdo. Lisboa: Edições 70, 2000.

BORGES, Márcio. Os sonhos não envelhecem: histórias do Clube da Esquina. São Paulo: Geração Editorial, 1996.

BRASIL. Secretaria de Educação Fundamental. Parâmetros curriculares nacionais: terceiro e quarto ciclos do ensino fundamental: introdução aos parâmetros curriculares nacionais / Secretaria de Educação Fundamental. Brasília: MEC/SEF, 1998.

DEL PRIORE, Mary. História das crianças no Brasil. 5 ed. São Paulo: Contexto, 2006.

D'INACIO, Maria Angela. Mulher e família burguesa. In: DEL PRIORE, Mary (Org.). História das mulheres no Brasil. São Paulo: Contexto, 2004.

GOUDARD, Phelippe. A estética do riso: do corpo sacrificado ao corpo abandonado. In: WALLON, Emmanuel (Org.). O circo no risco da arte. Belo Horizonte: Autêntica, p. 25-31, 2009.

HALL, S. Identidade cultural na pós-modernidade. Rio de Janeiro: DP\&A, 2006.

MOSCOVICI, Serge. A representação social da psicanálise. Rio de Janeiro: Zahar, 1978.

NASCIMENTO, Milton; BASTOS, Ronaldo. Circo marimbondo. In: NASCIMENTO, Milton. Geraes. Rio de Janeiro: EMI/ODEON, 1976. 1 CD: digital, estéreo. 61.192.473

NORA, P. Les lieux de mémorie. Paris: Editions Gallimard, 1984.

OSTROWER, Fayga. Criatividade e processos de criação. Petrópolis: Vozes, 1987. 
SCHIELE, Bernard; BOUCHER, Louise. A exposição científica: uma maneira de representar a ciência. In: JODELET, Denise (Org.). As representações sociais. Rio de Janeiro: Eduerj, p. 363-377, 2001. 


\section{Anexo (Letra de Circo Marimbondo)}

Circo Marimbo

Circo Marimbondo

Circo Marambaia

Eu cheguei de longe

Não me "atrapaia"

Vê se não me amola

Larga a minha saia

Circo Marimbondo

Circo Marambaia

Se eu te der um tombo

Tomara que caia

Circo Marimbondo

Circo Marambaia 